\title{
DESIGN AND FORMABILITY ANALYSIS OF FENDER COMPONENT
}

\author{
Sanjay Kumar S.M'， D.P.Girish ${ }^{2}$ \\ ${ }^{1}$ Associate Professor, Department of Mechanical Engineering, Brindavan College of Engineering, Bangalore- \\ 560063. \\ sanjay20376@gmail.com \\ ${ }^{2}$ Professor \& HOD, Department of Mechanical Engineering, Govt. Engineering College, Ramanagara, Karnataka., \\ omganesha16@gmail.com
}

\begin{abstract}
Fender is a front outerside member of a car, which covers the wheel side. It has so many small features with ups and downs. The binder surface is not a planer one in this case. This is because to reduce the draw depth and it has two rows of draw beads. It seems to be difficult to form due to their small radius fillets. In this analysis, there is a need to find out the forming feasibility of this component and if not possible in single stage then we need to modify the die design with least modification and need to optimize the draw bead profile and draw radius in such a way that we can get the good component in a single stage itself. For thin and very big forming dies, we need to do gravity analysis. If our die face is profiled one, then we may need to do binder wrap analysis. The binder wrap analysis results are taken to the forming analysis. After the forming analysis, if trimming is there means just before trimming analysis we have to do mesh coarsening. Then the coarsened mesh and its results are taken for trimming analysis. The results of the trimming analysis are taken to the spring back analysis. From the results of the spring back analysis, further we can cross check the spring back of the real component. The analysis results obtained is used in sheet metal industry for metal forming process.
\end{abstract}

Keywords: Fender, Binder Wrap Analysis, Tonnage, Forming, Die, etc.

\section{INTRODUCTION}

The use of simulation software in metal forming process has increased significantly in recent years as the benefit of troubleshooting and optimizing process on the computer rather than through extensive shop floor trials have been realized. The rapid development of software technology, together with faster and lower cost computer hardware, have recently enabled many manufacturing operations to be modeled cost-effectively that only a few years ago would have been considered impractical. Many of these advances have been made possible by tailoring and optimizing programs for specific applications, which has resulted in the general terms of "sheet forming" and "bulk forming" applied to different types of process modeling software. However, the choice of software for an uninitiated company is not always as simple as this classification. For examples, sheet metal forming is currently developing much interest in the globe as a means of reducing both the development cost of stamping a new part and the production lead-time. These costs are accumulated over the entire development process from initial part design to the final production tool. The correct software tool will depend on both the application and the stage of product development.

Design of sheet metal forming is traditionally relying on the experience accumulated by tool design engineers through long and costly trial and error experiments. Simple empirical methods provide some guidelines for cases similar to those on which these methods were developed. In increasing number of cases with complex geometry's and thinner stronger materials, experiments are used extensively consuming time and money before providing a workable solution. These experiments usually lead to one severity conclusion (the pressed part fails or not) with little if any information on the safety margin.

The arising need to produce more complex parts in the most economic way calls for a tool design methodology capable of providing the engineer with a more detailed insight of the physical behaviour. This applies especially for parts made of new materials for which experience lacks

Another strain on the overall design cycle of a new product in the traditional approach results from the fact that before prototypes for testing can be manufactured a whole series of preliminary tasks must be carried out (sequential engineering). The target of a 'fast-to-the market' release of new products ideally requires a simultaneous engineering approach in which the assessment of manufacturability can be explored as early as possible in the design cycle.

These emerging needs called for a new tool design methodology based on numerical simulation. The new CAE methodology investigates and simulates the physical phenomena developing during sheet metal forming. This is achieved by using a numerical simulation tool -, HYPER FORM, L.S -DYNA, DYNAFORM, PAM-STAMP etcwhich is used throughout a multistep design processformability evaluation with numerical simulation (FENS). This approach provides the design engineers with a detailed insight or what is happening in sheet metal forming and which are the causes of troubles, thus easing their solutions. 


\section{EXPERIMENTAL STUDY}

In this analysis, it has to be find out the forming feasibility of this component and if not possible in single stage then we need to modify the die design with least modification and need to optimize the draw bead profile and draw radius in such a way that we can get the good component in a single stage itself.

The product is "FENDER" with $0.6 \mathrm{~mm}$ sheet thickness. It is a front outer side member of a car, which covers the wheel side. It has so many small features with Ups and downs as shown fig.2.1 and 2.2. The first figure shows the component and the second one shows the die for that component.

The binder surface is not a planer one. This is because to reduce the draw depth and it has two rows of draw beads. It seems to be difficult to form due to their small radius fillets. The component has to be analysed with gravity,binder wrap and forming analysis.

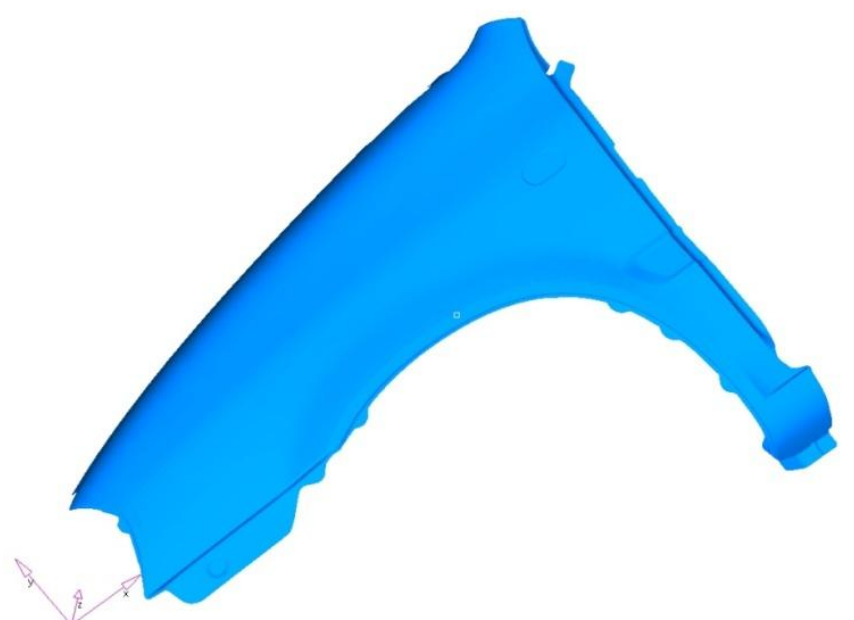

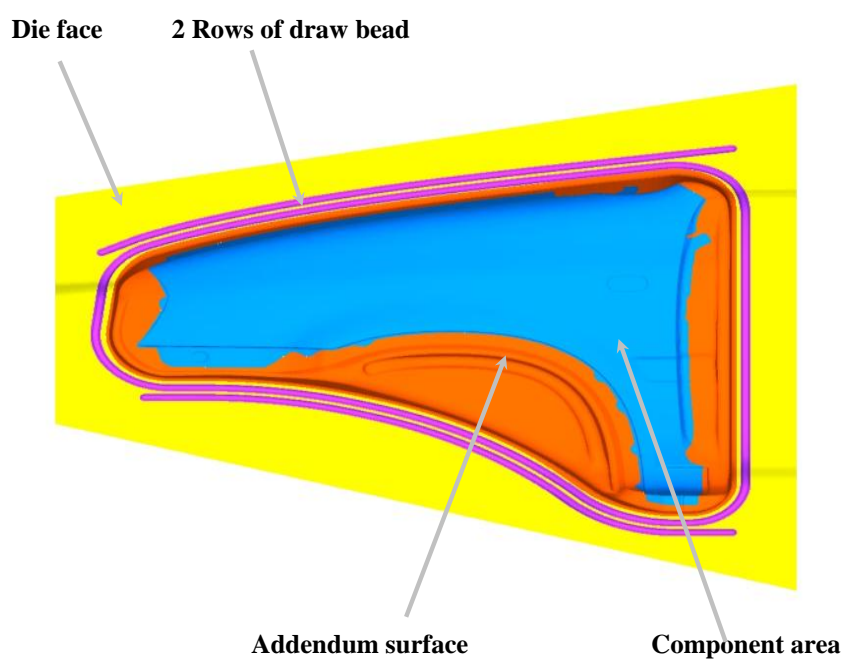

Fig.2.2 Model of fender component

$\begin{array}{ll}\text { Specifications } & \\ \text { Type of machine } & =0.6 \mathrm{~mm} ; \\ \text { Thickness } & =\mathrm{SPC} 440 ; \\ \text { Material } & =7.8 \mathrm{e}-9 \mathrm{~N} / \mathrm{mm} 3 ; \\ \text { Density } & =210000 \mathrm{~N} / \mathrm{mm} ; \\ \text { Young's modulus (E) } & =0.3 \\ \text { Poisson's ratio (Nu) } & =310 \mathrm{Mpa} \\ \text { Yield strength (Y.S) } & =1.6 \\ \text { Plastic an-isotropic co-efficient (r) } & =>440 \mathrm{Mpa} \\ \text { Tensile strength (T.S) } & =0.18 \\ \text { Strain hardening exponent (n) } & \\ \text { Strain hardening co-efficient }(\mathrm{k}) & =720 \\ \% \text { Elongation } & =29 \text { to } 40\end{array}$

\section{ANALYSIS RESULTS AND DISCUSSIONS}

Iteration was carried out for different tonnages. Different quality output was obtained as shown in table below.

Fig.2.1. Model of a Fender Component

Table 3.1 Quality Output For Different Tonnage Changes Using HYPERFORM/LS-DYNA

\begin{tabular}{|c|c|c|c|c|}
\hline ITERATION & $\begin{array}{l}\text { TONNAGE } \\
\text { CHANGES }\end{array}$ & $\begin{array}{l}\text { THICKNESS } \\
\text { MIN TO MAX }\end{array}$ & $\begin{array}{l}\text { \% THINNING } \\
\text { MIN TO MAX }\end{array}$ & QUALITY \\
\hline 1 & $\begin{array}{r}45 \\
\text { DEFAULT }\end{array}$ & 0.0371 TO 0.9412 & -152.4 TO 93.8 & Very Bad \\
\hline 2 & $\begin{array}{r}30 \\
\text { DEFAULT }\end{array}$ & & & Very Bad \\
\hline 3 & $\begin{array}{r}25 \\
\text { DEFAULT } \\
\end{array}$ & 0.102 TO 0.9085 & $-151.4 \quad$ TO 83 & Very Bad \\
\hline 4 & $\begin{array}{r}40 \\
\text { Draw bead removed to } \\
130,480 \mathrm{~mm} \text { in } 2 \text { places }\end{array}$ & & & Very Bad \\
\hline 5 & $\begin{array}{l}40 \\
\text { Draw bead removed to } \\
115,180 \mathrm{~mm} \text { in } 2 \text { places }\end{array}$ & & & Bit improved \\
\hline 6 & 40 & 0.2056 TO 0.8502 & -41.71 TO 65.74 & Bit improved \\
\hline
\end{tabular}




\begin{tabular}{|l|r|r|l|l|}
\hline & $\begin{array}{r}\text { More generous corner } \\
\text { radius }\end{array}$ & & & \\
\hline $\mathbf{7}$ & $\begin{array}{r}40 \\
\text { Draw bead removed to } \\
530 \mathrm{~mm} \text { in 1 place }\end{array}$ & & & \\
\hline $\mathbf{8}$ & $\begin{array}{r}\text { Draw bead removed to } \\
260 \mathrm{~mm} \text { in 1 place }\end{array}$ & & & \\
& $\begin{array}{r}40 \\
\mathbf{9}\end{array}$ & & & Satisfactory \\
\hline & $\begin{array}{r}\text { Die radius changed from } \\
10 \text { to } 14 \mathrm{~mm} \& \text { Draw bead } \\
\text { removed to } 250 \mathrm{~mm} \text { in 1 } \\
\text { place }\end{array}$ & 0.38 TO 0.654 & -9.48 TO 36.85 & $\begin{array}{l}\text { Good Formability } \\
\text { achieved }\end{array}$ \\
\hline
\end{tabular}

Initially, upto five iteration quality was very bad. Further iterations shows improved quality little bit. Lastly, iteration at ninth stage good formability was obtained.

\section{CONCLUSION}

1. The fender is analyzed for finding the forming feasibilityand it is formable in a single stage. On this process, we could be able to optimize the die design, draw radius, blank holding force, draw bead profile etc.

2. For thin and very big forming dies we need to do gravity analysis. If our die face in profiled one then we may need to do binder wrap analysis.

3. The coarsened mesh and its results are taken for trimming analysis.

4. The results of the trimming analysis are taken to the spring back analysis. From the results of the spring back analysis, we can cross check the spring back of the real component.

\section{REFERENCES:}

[1]. Joseph Carpenter, Mark T. Smith, November 2002. "Superplastic forming of aluminum sheet metal for automotive applications", Bulletin of Transportation for the 21st Century.

[2]. V.Pancholi, B.P.Kashyap, March 2003, "Effect of local strain distribution on concurrent microstructural evolution during superplastic deformation of $\mathrm{Al}-\mathrm{Li}$ 8090 alloy", Material Science \& Engineering Conference, 1 pp.

[3]. B. Davisand J. Hryn, 15 December 2007, "Innovative Forming and Fabrication Technologies: New Opportunities", Argonne National Laboratory U.S., pp: $2-41$.

[4]. ZhipengZeng, Yanshu Zhang, Yi Zhou, 2005, "Superplastic Forming of Aluminum Alloy Car Body panels", Material science forum, Trans Tech Publications, pp $1-4$.

[5]. J. Hirsch, 2004, "Automotive Trends in Aluminium The European Perspective", Materials Forum, Institute of Materials Engineering Australasia Ltd, vol 28, pp 19-20.

[6]. PushkrajVasantDeshmukh, 2003 "Study of Superplastic Forming Process using Finite Element Analysis", PhD Thesis, University of Kentuky, pp: 118.
[7]. V.Pancholi, B.P.Kashyap, 2007, "Effect of layered microstructure on superplastic forming property of AA8090 Al-Li alloy", Journal of Material Processing Technology, pp 1.

[8]. Wang Zhongjun*, Wang Zhaojing, Zhu Jing, 2011 "Superplastic deformation of a relatively coarsegrained AZ80 magnesium alloy", Advance Materials Letters, vol 2, pp 113-117. 